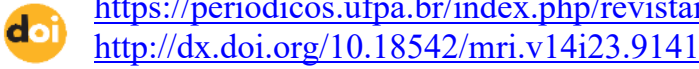

\title{
COLONIALIDADE, GÊNERO E MERCADO DE TRABALHO: UM DIÁLOGO ENTRE A BIOPOLÍTICA E A NECROPOLÍTICA
}

\section{COLONIALITY, GENDER AND LABOR MARKET: A DIALOGUE BETWEEN BIOPOLITICS AND NECROPOLITICS

\author{
Maritânia Salete Salvi RAFAGNIN ${ }^{1}$ \\ Universidade Católica de Pelotas \\ Tiago LEMÕES ${ }^{2}$ \\ Universidade Católica de Pelotas
}

\begin{abstract}
Resumo: Faz-se uma leitura da classe trabalhadora no contexto moderno-colonial utilizando-se das categorias da biopolítica de Foucault e necropolítica de Mbembe. Tais categorias são utilizadas como metodologia de análise dos fenômenos na periferia do capitalismo. Os resultados demonstram que, a produção de valores sempre foi relacionada ao trabalho vivo, contudo, com o advento da reestruturação produtiva, baseada na acumulação flexível, as empresas, descartaram a mão-de-obra (agora sobrante ao capitalismo), além do fato dos trabalhadores que mantiveram seus empregos, passaram a acumular diversas funções. Portanto, identificou-se que a precarização da vida tem incidido sobre a classe trabalhadora, submetida, cada vez mais, a novas formas de exploração da força de trabalho, sendo que na biopolítica inserem-se os trabalhadores formais e na necropolítica, os informais. Isso porque, o padrão que rege a sociedade capitalista é baseado nos valores de troca de mercadorias, logo, o sujeito não inserido nesse processo, é desnecessário para o sistema.
\end{abstract}

Palavras-chave: Classe Trabalhadora. Biopolítica. Necropolítica.

\begin{abstract}
A reading of the working class in the modern-colonial context is made using the categories of Foucault's biopolitics and Mbembe's necropolitics. Such categories are used as a methodology for analyzing phenomena on the periphery of capitalism. The results show that the production of values has always been related to live work, however, with the advent of productive restructuring, based on flexible accumulation, companies have discarded labor (now under capitalism), in addition to the fact of the workers who kept their jobs, started to accumulate several functions. Therefore, it was identified that the precariousness of life has affected the working class, which is increasingly subjected to new forms of exploitation of the workforce, with formal workers in the biopolitics and informal workers in the necropolitics. This is because, the standard that governs capitalist society is based on the exchange values of goods, therefore, the subject not inserted in this process, is unnecessary for the system.
\end{abstract}

Keywords: Working class. Biopolitics. Necropolitics.

\footnotetext{
${ }^{1}$ Doutoranda em Política Social e Direitos Humanos em Política Social pela Universidade Católica de Pelotas. Bolsista CAPES. E-mail: mari.salvi@gmail.com

${ }^{2}$ Doutor em Antropologia Social pela Universidade Federal do Rio Grande do Sul. Professor do Programa de PósGraduação em Política Social e Direitos Humanos da Universidade Católica de Pelotas (PPG-PSDH/UCPel). E-mail: tiagolemoes@gmail.com
} 
O sistema é muito racional do ponto de vista de seus donos estrangeiros e de nossa burguesia comissionista, que vendeu a alma ao Diabo por um preço que deixaria Fausto envergonhado. Mas o sistema é tão irracional para todos os outros que, quanto mais se desenvolve, mais aguça seus desequilíbrios e tensões, suas candentes contradições. Até a industrialização, dependente e tardia, que comodamente coexiste com o latifúndio e as estruturas da desigualdade, contribui para semear o desemprego, em vez de ajudar a resolvê-lo; alastra-se a pobreza e se concentra a riqueza nesta região de imensas legiões de braços cruzados que se multiplicam sem parar. Novas fábricas se estabelecem nos polos privilegiados do desenvolvimento - São Paulo, Buenos Aires, Cidade do México - e cada vez menos mão de obra eles necessitam.

O sistema não previu este pequeno incômodo: o que sobra é gente. E gente se reproduz. Faz-se amor com entusiasmo e sem precauções. Cada vez resta mais gente à beira do caminho, sem trabalho no campo, onde o latifúndio reina com suas gigantescas terras improdutivas, e sem trabalho na cidade, onde reinam as máquinas: o sistema vomita homens. (GALEANO, 2016, p. 21).

\section{INTRODUÇÃO}

Produzir uma reflexão teórica sobre o mercado de trabalho, no contexto brasileiro, em tempos de crise, é de fato um desafio, pois no plano dos direitos sociais conquistados, o neoliberalismo tem promovido a retirada de cada um deles. Para realizar uma reflexão preliminar - em diálogo com inferências produzidas no campo da teoria pós-colonial e em estudos de gênero - sobre o cenário de desmonte de frágeis garantias fundamentais conquistadas a muito custo, sobretudo no contexto latinoamericano, lançaremos mão de dois conceitos que julgamos imprescindíveis ao que pretendemos perscrutar: a biopolítica, explorada pelo pensador francês Michel Foucault, e as reflexões decorrentes da noção de necropolítica, formuladas pelo teórico camaronês Achille Mbembe.

De imediato, julgamos necessária uma diferenciação: ao contrário de Mbembe $(2017 ; 2019)$, que explora a perversidade histórica dos processos de colonização nas periferias do capitalismo, as reflexões foucaultianas voltam-se para a analítica do poder e do saber (sobre o corpo, a espécie humana e a população) em contextos históricos, sociais e institucionais predominantemente europeus. No entanto, tal distinção não nos serve como razão para o rechaço das contribuições de Michel Foucault - um dos mais complexos e influentes intelectuais do século XX. Como bem argumenta Hilário (2016), mesmo entendendo a pertinência da crítica em relação à sua localização eurocêntrica, os mecanismos de poder propostos por Foucault permitem "[...] olhar para a periferia e analisar os modos pelos quais os dispositivos de análise foucaultianos funcionam ou não" (HILÁRIO, 2016, p. 197).

Tal postura implica considerar a potência de determinados conceitos como bússola para identificar continuidades e inflexões nos modos de operação do poder, discriminando seriamente a geopolítica e as experiências históricas, sociais e culturais dos cenários em análise. Por isso, 
utilizaremos a noção de biopolítica - e os processos de regulação da saúde, do corpo, da alimentação e da proteção social que a definem, para elucidar os efeitos perversos do colonialismo e do neoliberalismo inserido no contexto moderno-colonial.

Justamente pela opção de diálogo com Foucault, mas sem perder de vista as possibilidades de crítica e atualização de seu pensamento, é que trazemos ao texto as contribuições de Mbembe, autor que, por meio da noção de necropolítica, atualiza algumas inferências foulcaultianas para fenômenos situados na periferia do capitalismo, mais especificamente aqueles que remetem a passagem da biopolítica para a necropolítica. Para potencializar e complexificar nossa proposta analítica, faremos conexões com as noções de colonialidade do poder (QUIJANO, 2010) e da colonialidade de gênero (LUGONES, 2014), dada a importância da localização do discurso, para que se compreenda a realidade experienciada pela mulher trabalhadora.

Entendemos que a necessidade de discussão destas últimas categorias - que serão esmiuçadas a seguir - para a leitura especificamente da mulher trabalhadora no contexto brasileiro, reside na incongruência entre conceitos clássicos e a nova realidade que se apresenta. Nesse sentido, conforme alerta Cláudia Costa (2010, p. 45), em vista das “[...] profundas mudanças ocasionadas pelos processos cada vez mais intensificados da globalização, as categorias tradicionais de análise (incluindo as marxistas) já não abarcam totalmente as transformações identitárias, geopolíticas, econômicas e culturais do mundo atual". Por isso, ao articularmos as categorias aqui elencadas, valorizando os efeitos analíticos da biopolítica e necropolítica, iluminaremos algumas formas de poder que vigoram na periferia capitalista, as quais se desdobram em novos processos de barbárie, relacionados diretamente com políticas da vida e da morte.

\section{ARTICULANDO O MARCO TEÓRICO}

Para melhor situarmos a categoria biopolítica, nos deteremos em breves considerações acerca dos mecanismos, técnicas e tecnologias de poder incididas, em um primeiro momento, sobre o corpo, e, em seguida, sobre a população - tomada como objeto de reflexão e intervenção estatal. Nesta perspectiva, inicialmente o corpo assume uma realidade política mais precisamente porque

[...] as relações de poder têm alcance imediato sobre ele; elas o investem, o marcam, o dirigem, o supliciam, sujeitam-no a trabalhos, obrigam-no a cerimônias, exigemlhe sinais. Este investimento político do corpo está ligado, segundo relações complexas e recíprocas, à sua utilização econômica; é, numa boa proporção, como força de produção que o corpo é investido por relações de poder e de dominação; mas em compensação sua constituição como força de trabalho só é possível se ele está preso num sistema de sujeição (onde a necessidade é também um instrumento 
político cuidadosamente organizado, calculado e utilizado); o corpo só se torna força útil se é ao mesmo tempo corpo produtivo e corpo submisso. (FOUCAULT, 1999a, p. 29).

Com isso, podemos inferir que as relações de poder são, no contexto de emergência da modernidade, relações produtivas, que se tornam mais eficientes a medida em que o corpo que produz é também um corpo submisso, controlado e adestrado. No entanto, é prudente que este poder seja compreendido a partir de sua microfísica, com base em sua incidência sobre corpos individuais em suas práticas cotidianas, porquanto as relações de poder estão entre as coisas mais ocultas no corpo social (FOUCAULT, 1984). Mais especificamente, as técnicas de poder, centradas no corpo individual, são compreendidas como o conjunto de

[...] procedimentos pelos quais se assegurava a distribuição espacial dos corpos individuais (sua separação, seu alinhamento, sua colocação em série e em vigilância) e a organização, em torno desses corpos individuais, de todo um campo de visibilidade. Eram também as técnicas pelas quais se incumbiam desses corpos, tentavam aumentar-lhes a força útil através do exercício, do treinamento, etc. Eram igualmente técnicas de racionalização e de economia estrita de um poder que devia se exercer, da maneira menos onerosa possível, mediante todo um sistema de vigilância, de hierarquias, de inspeções, de escriturações, de relatórios: toda essa tecnologia que podemos chamar de tecnologia disciplinar. (FOUCAULT, 1999b, p. 288).

A tecnologia disciplinar, portanto, sujeita corpos a processos de docilização, tornando-os uma máquina de produção, através de normas, preceitos, proibições, eliminando desvios e anomalias (HILÁRIO, 2016). Conforme Hilário (2016) o poder disciplinar não se trata de um poder de morte, mas de um poder de vida, do qual sua função não é matar, mas sim, operar impositivamente sobre a vida.

Especificamente na segunda metade do século XVIII, Foucault observa que as disciplinas, empregadas sobretudo nas fábricas, nos hospitais, nos manicômios, nas escolas e nas prisões, estavam perdendo parte da eficácia da manutenção do seu poder. É exatamente neste recorte temporal de inflexões que Foucault identifica o surgimento de uma nova tecnologia "[...] que não exclui a técnica disciplinar, mas que a embute, que a integra, que a modifica parcialmente e que, sobretudo, vai utilizála implantando-se de certo modo nela e incrustando-se efetivamente graças a essa técnica disciplinar prévia" (FOUCAULT, 1999b, p. 289). Essa tecnologia o autor denomina de biopolítica, que atua sobre o homem-espécie, afetando o conjunto de "[...] processos que são próprios da vida, como o nascimento, a morte, a produção, a doença, etc." (FOUCAULT, 1999b, p. 289). Concordamos, assim, que a biopolítica congrega uma série de 
[...] fenômenos que se começa a levar em conta no final do século XVIII e que trazem a introdução de uma medicina que vai ter, agora, a função de uma higiene pública, com organismos de coordenação dos tratamentos médicos, de centralização da informação, de normalização do saber, e que adquire também o aspecto de campanha de aprendizado da higiene e de medicalização da população. Portanto, problemas da reprodução, da natalidade, problemas da morbidade também. $\mathrm{O}$ outro campo de intervenção da biopolítica vai ser todo um conjunto de fenômenos dos quais uns são universais e outros são acidentais, mas que, de uma parte, nunca são inteiramente compreensíveis, mesmo que sejam acidentais, e que acarretam também consequências análogas de incapacidade, de pôr indivíduos fora de circuito, de neutralização, etc. Será o problema muito importante, já no início do século XIX (na hora da industrialização), da velhice, do indivíduo que cai, em consequência, para fora do campo de capacidade, de atividade. E, da outra parte, os acidentes, as enfermidades, as anomalias diversas. É em relação a estes fenômenos que essa biopolítica vai introduzir não somente instituições de assistência (que existem faz muito tempo), mas mecanismos muito mais sutis, economicamente muito mais racionais do que a grande assistência, a um só tempo maciça e lacunar, que era essencialmente vinculada à Igreja. Vamos ter mecanismos mais sutis, mais racionais, de seguros, de poupança individual e coletiva, de seguridade, etc. (FOUCAULT, 1999b, p. 291).

A biopolítica, deste modo, tornou-se um elemento indispensável para o desenvolvimento do capitalismo, uma vez que garantiu a inserção controlada dos corpos no aparelho de produção, ajustando, consequentemente, não somente os corpos disciplinados, mas também a população aos processos econômicos (HILÁRIO, 2016). E isso ocorre precisamente porque como um problema político, a população é o terreno no qual a biopolítica vai regulamentar a vida e disciplinar o corpo, modificando assim o poder político para o direito de fazer viver e deixar morrer: um poder que, ao mesmo tempo em que se esforça no prolongamento e multiplicação de vidas, também pode matar e deixar morrer.

Nesta nova configuração política que se consolida sobretudo a partir do século XIX, o racismo assume um papel central no funcionamento do Estado biopolítico. Enquanto uma censura de tipo biológico, o racismo introduz um corte entre quem deve viver e quem deve morrer, justificando a morte em nome do fortalecimento da raça e da espécie, de modo que a morte de uns potencializa e otimiza a vida de outros (FOUCAULT, 1999b). Assim, nos cabe considerar que se por um lado a biopolítica implica em uma gestão da vida, ela também produz a gestão da morte, na medida em que para fortalecer a vida e sua produtividade, é necessário que outros morram ou sejam alvo de uma série de precarizações, vulnerabilizações e violências. 


\section{PERVERSIDADES NEOLIBERAIS: REFLEXões DESDE O PENSAMENTO PÓS E DECOLONIAL}

Foucault inicia a elaboração de suas reflexões sobre poder disciplinar e bipoder em um momento em que o capitalismo estava em expansão, relacionado aos modos de produção fordista/taylorista aliados ao Welfare State. Com efeito, a partir da década de 1970, esse modelo demonstra sinais de esgotamento, obrigando o sistema capitalista de produção a se reinventar sob a ótica neoliberal, acompanhado da reestruturação produtiva baseada no modelo de acumulação flexível.

Com a alteração do modo de produção e da ofensiva política do capital proposta pelo neoliberalismo, alteram-se, consequentemente, as relações entre o corpo e o poder. Isso porque, sob a ótica neoliberal, foi dispensado um grande contingente de trabalhadores, principalmente nos países capitalistas periféricos. Em relação a este fenômeno, Santos (2016, p. 42) observa que:

Em decorrência desses processos [neoliberalismo e reestruturação produtiva], o capital assume novos padrões de produção, de acumulação e concorrência, que afetam diretamente a classe trabalhadora. $\mathrm{O}$ processo produtivo da sociedade capitalista neoliberal exige mais eficácia, promovendo um salto no desenvolvimento tecnológico, na informatização, que, consequentemente, atingem os processos e relações de trabalho. Percebe-se então que as mudanças no mundo do trabalho procedem de alguns vetores principais, mutuamente implicados: de um lado, a reestruturação produtiva (centrada na introdução da informática e da automação no processo produtivo, ela conduz a mudanças na organização do trabalho - produção flexível e trabalho polivalente), que substitui o modelo fordista anterior; de outro lado a descentralização produtiva e a terceirização. Associada a esse processo, observa-se uma tendência à desregulamentação dos mercados nacionais. É nesse contexto que o desemprego assume hoje um sentido estrutural, do mesmo modo que as formas precarizadas de trabalho - o subemprego (SANTOS, 2016, p. 42).

Assim, em termos econômicos, ainda que a produção de valores esteja relacionada ao trabalho vivo, o aumento da maquinaria nas fábricas passou a descartar os sujeitos, que se tornaram sobrantes. Com o crescente desemprego, intensificaram-se as formas de precarização do trabalho, que se traduzem em novos modos de adoecer e morrer da classe trabalhadora.

Esse processo tem como marco a passagem da biopolítica para a necropolítica, uma vez que não se tem mais

[...] uma política voltada para a produção de vida - ainda que adequada à forma social, [...] - e sim uma política cujo objetivo é a aniquilação em larga escala. Aqui a tendência para o 'trabalho morto' na produção de valor encontra o 'trabalho de morte' da política. Os indivíduos começam a sobrar diante da forma social atual, pois já não são mais rentáveis, não são mais requisitados a dispenderem sua força de trabalho no interior do processo produtivo amplo. Muito pelo contrário, são expulsos 
e jogados no mercado informal e precário, nas margens da cidade etc. (HILÁRIO, 2016, p. 203).

Logo, em um Estado de cunho neoliberal, que defende a retirada dos direitos sociais, ao invés da produção de um "trabalho de vida", com pessoas sadias para produzir riqueza, tem-se um "trabalho de morte", ou melhor: um conjunto de intervenções que produz zonas nas quais determinados sujeitos são expostos à morte ou a vulnerabilização em suas múltiplas formas.

Diante disso, verifica-se que as massas de trabalhadores, considerados supérfluos, passam a viver em um estado de absoluta precariedade, pois o sistema econômico-social não tem lugar para todos. Essas pessoas passam a ocupar as bordas do mundo social, com condições precárias de vida ou mesmo em situação de sobrevida. Esses corpos, considerados sobrantes ao sistema, não mais necessários para a reprodução do capital, “[...] são submetidos a condições de vida que lhes conferem o status de "mortos-vivos"” (MBEMBE, 2016, p. 146), afinal, são portadores de uma vida descartável.

Essa realidade se faz presente em países latino-americanos, como o Brasil, onde a ordem democrática e a colonial estão absolutamente conectadas. A democracia e o "[...] império colonial fazem objetivamente parte de uma mesma matriz histórica. Este fato originário e estruturante é central a qualquer compreensão histórica da violência da ordem mundial contemporânea” (MBEMBE, 2017, p. 43).

Observa-se, então, que a necropolítica - essa subjugação contemporânea da vida ao poder da morte - se constitui como categoria fundamental para se pensar a realidade de países colonizados, principalmente, para entender que se as tecnologias de extermínio e exclusão possuem alvos racialmente marcados, também atingem, com intensidades diferentes, as populações não-negras, também cada vez mais precarizadas (LIMA, 2018).

Nessa senda, verifica-se que a precarização da classe trabalhadora, mesmo se apresentando como marca do modo capitalista de produção como um todo, nos países periféricos colonizados, se apresenta com novos desdobramentos da questão social, cujos corpos dos trabalhadores trazem consigo as marcas da lógica excludente desse sistema. Isso porque, esses corpos descartáveis, estão inseridos numa lógica de colonialidade de poder e de classificação social, pois,

[...] cada forma de controle de trabalho esteve articulada com uma raça particular. Consequentemente, o controle de uma forma específica de trabalho podia ser ao mesmo tempo um controle de grupo específico de gente dominada. Uma nova tecnologia de dominação/exploração, neste caso raça/trabalho, articulou-se de maneira que aparecesse como naturalmente associada, o que, até o momento, tem sido excepcionalmente bem-sucedido. (QUIJANO, 2010, p. 109). 
Desde o começo da América, os europeus associaram o trabalho não pago ou não-assalariado às raças colonizadas, porque eram consideradas inferiores, desenvolvendo-se a percepção de que o trabalho assalariado era privilégio branco. Tal inferioridade racial produzida sobre populações colonizadas implicou em certa naturalização do trabalho em benefício dos seus amos - posição essa que se pode encontrar até os dias atuais em diversos lugares do mundo (QUIJANO, 2010). Logo, pode-se constatar que a colonialidade sempre foi elemento legitimador das diferenças biológicas, silenciando-as nos termos das relações de poder.

Porém, conforme assevera Costa (2010) no conceito da colonialidade do poder de Quijano, tem-se a ideia de raça como elemento estruturante do colonialismo e das suas manifestações neocoloniais, faltando analisar a questão do gênero enquanto elemento estruturador e não subordinado da colonialidade do poder. Nesse mesmo sentido, de acordo com Lugones (2014) a intersecção entre raça, classe, sexualidade e gênero permite compreender definitivamente que as mulheres não brancas, são justamente as mais submetidas à lógica de opressão do poder moderno-colonial.

\section{COLONIALIDADE, GÊNERO E MERCADO DE TRABALHO}

Ao levarmos a sério os ensinamentos de teóricos pós-coloniais e decoloniais, consideramos que a América Latina carrega em suas memórias mais de três séculos de escravidão e extermínio de indígenas e africanos, o que repercute, atualmente, nas relações sociais, principalmente na composição do mercado de trabalho. Especificamente no Brasil, ainda que entre os anos de 1950 a 2010 a participação feminina no trabalho remunerado tenha mais que triplicado, de 13,6\% para $49,9 \%$, ao passo que a masculina decresceu de $80,8 \%$ para $67,1 \%$, as mulheres enfrentam disparidade de rendimentos, agravando-se quando se focaliza a questão racial, uma vez que um homem branco recebe quase o dobro de uma mulher negra que detém o mesmo nível de escolaridade (ANDRADE, 2016). Ademais, conforme pesquisa realizada pelo Departamento Intersindical de Estatística e Estudos Socioeconômicos (DIEESE),

$[\ldots]$ as mulheres enfrentam grandes dificuldade no mercado de trabalho, representam mais da metade da população desempregada e, quando ocupadas, percebem rendimentos menores do que o dos homens. A discriminação de gênero é um fator determinante para as possibilidades de acesso, permanência e condições de trabalho. A necessidade de transformar as condições nas quais elas se inserem e estão inseridas, constitui-se um desafio relevante para a construção de novas relações sociais. Historicamente, a abordagem por sexo revela que as mulheres enfrentam grandes dificuldades no mercado de trabalho, tanto para conseguir uma ocupação como para mantê-la e, principalmente por auferir rendimentos menores do que os homens DIEESE (2013, p. 01). 
Também, acerca da desigualdade de gênero e raça, aduz Andrade (2016) que enquanto o homem branco inativo tem média de idade de 65,7 anos, possui renda média de R $\$ 1934$ e número médio de filhos de 0,6, as mulheres negras inativas estão no extremo oposto: sua idade média é de 49 anos - quase 17 anos a menos que o homem branco, sua renda média é de R $\$ 786$ - representando $40 \%$ da deles, e possuem mais que o dobro de filhos, 1,3 .

Ademais, segundo pesquisa realizada pelo IPEA (2016, p. 10) no Brasil, “[...] 44,2\% das mulheres negras não são contribuintes da previdência social, seguidas de perto pelos homens negros $(43,7 \%)$ ". Tais números indicam a baixa qualidade dos postos de trabalho, já que essa população está totalmente desprotegida em caso de desemprego ou de acidentes laborais.

Em vista desses dados, identifica-se a persistência das relações coloniais, pois o homem negro e mais ainda, a mulher negra, além de auferir renda inferior quando comparada ao homem e a mulher branca, encontram maior dificuldade de acessar o mercado formal de trabalho - estando, deste modo, excluídos do sistema de proteção social.

Há que se considerar, também,

[...] que o mercado de trabalho brasileiro sempre foi segmentado pelo menos em dois: um mercado de trabalho formal, no qual os trabalhadores tinham os direitos trabalhistas e previdenciários garantidos por força da lei, e um mercado informal, no qual os salários, a jornada e as condições de trabalho não tinham o amparo da lei e no qual os trabalhadores não tinham acesso aos benefícios previdenciários. A existência desse mercado, que compreende mais ou menos $50 \%$ dos ocupados, é um dos traços que nos identifica com os demais países da América Latina e faz com que estruturalmente parte do mercado de trabalho apresente certo nível de flexibilidade. Contudo, é preciso lembrar que os trabalhadores, que integram cada segmento, não são completamente intercambiáveis, sendo somente uma franja que ora está em um, ora em outro, e que a capacidade de intercambiabilidade depende dos requisitos necessários exigidos pelo setor de atividade que emprega o trabalhador. O percentual maior ou menor de ocupados na informalidade somente foi reduzido durante os governos Lula e Dilma, mas voltou a aumentar na crise recente. (MARQUES, UGINO, 2017, p. 17).

Logo, existem trabalhadores que sequer acessam o emprego formal, além do fato de que desses dados apresentados acima, existe uma parcela da população que nem ao menos entra no computo das estatísticas, seja por serem indígenas, ou por estarem em situação de rua, não se enquadrando dentro dessa lógica de dominação capitalista proposta pela modernidade-colonial. Estes sujeitos vivenciam mais ainda a lógica de precarização do trabalho e de suas vidas, justamente por sua condição de extrema vulnerabilização. 


\section{ALGUMAS REFLEXÕES FINAIS?}

Neste artigo, buscamos fazer uma leitura da colonialidade, gênero e mercado de trabalho, no contexto moderno-colonial, utilizando as categorias da biopolítica de Foucault e necropolítica de Mbembe. A partir do exposto, verificamos que o foco da tecnologia disciplinar e da biopolítica tem sido a inserção controlada da população aos processos econômicos, garantindo a reprodução do sistema capitalista. Entretanto, tais categorias foram observadas num período em que os modos de produção fordista/taylorista aliados ao Welfare State estavam em plena ascensão.

Em meados de 1970, destacamos que esse sistema vigente começou a demonstrar sinais de seu esgotamento. Eis que o capitalismo se reinventa, com o processo de reestruturação produtiva, baseado no modelo de acumulação flexível, nos marcos do neoliberalismo. Sob essa ótica, o mercado de trabalho é profundamente afetado, tanto através das reduções de direitos laborais e terceirização, como pela automação e descentralização das fábricas, que extinguiu vários postos de trabalho, descartando inúmeros trabalhadores e submetendo àqueles que restaram nas fábricas a sobrecargas e jornadas extenuantes de trabalho.

Esse processo é o que entendemos como a passagem da biopolítica para a necropolítica, pois, no mercado de trabalho, passou-se a intensificar a concepção de "vidas descartáveis". Isso porque, os indivíduos sobrantes do sistema, são expulsos das fábricas, relegados informalidade e novas formas de precarização de seu labor.

Contudo, no contexto moderno-colonial, é preciso lembrar que o processo de exploração da mão de obra de trabalho sempre foi distinto do europeu, pois, desde o início da América, as raças colonizadas eram consideradas inferiores, e, portanto, deveriam ser exploradas. Conforme observamos na análise de Quijano (2010), esses corpos descartáveis inserem-se dentro de uma lógica de colonialidade de poder e de classificação social, sendo que no mercado de trabalho, a tecnologia de dominação/exploração opera sob a questão da raça/trabalho. Com isso, ocorre a naturalização de negros e indígenas serem mais explorados e submetidos a condições inferiores de trabalho do que os brancos.

Todavia, nosso debate buscou ir além dessa classificação de raça/trabalho, por concordar com a análise de Costa (2010) de que a questão do gênero também é fundamental nesse cenário, porquanto trata-se de um elemento estruturador e não subordinado da colonialidade do poder. A partir da proposta de Lugones (2014), através da intersecção entre raça, classe, sexualidade e gênero, foi possível identificar que as mulheres não brancas, são as mais submetidas à lógica de opressão do poder moderno-colonial. 
Verificou-se, ainda, que sobre os corpos - docilizados pelo poder disciplinar e biopolítico - o Estado, no contexto moderno-colonial, utiliza-se da necropolítica, afinal, sobrantes para o sistema, são relegados ao desemprego, ou ao subemprego (trabalho parcial, temporário, terceirizado ou subcontratado). Ainda é importante salientar que, nesse cenário, mesmo os trabalhadores e trabalhadoras que adoecem, sendo acometidas por alguma invalidez em virtude de doença adquirida pela atividade desempenhada, transformam-se em corpos inúteis ao mercado de trabalho. Muitos desembocam em zonas de não-humanidade, onde suas vidas perdem totalmente o valor e a capacidade de produzir comoção coletiva.

Por fim, entendemos estarmos longe de esgotar esse debate, porém apresentamos apenas algumas reflexões no sentido de (re)pensar sobre os processos de dominação/exploração que temos vivenciado no cotidiano, os quais se reinventam sob as novas faces da barbárie no sistema capitalista atual nos moldes do ideário neoliberal.

\section{Referências}

ANDRADE, Tânia. Mulheres no Mercado de Trabalho: Onde nasce a Desigualdade? Brasília: Consultoria Legislativa da Câmara dos Deputados, 2016.

COSTA, Cláudia. Feminismo, tradução cultural e a descolonização do saber. Fragmentos, Florianópolis, n. 39, p. 45-59, jul./dez., 2010. DOI: https://doi.org/10.5007/29649. Disponível em: https://periodicos.ufsc.br/index.php/fragmentos/article/view/29649. Acesso em: 20 set. 2019.

DIEESE. A inserção das mulheres nos mercados de trabalho metropolitanos e a desigualdade nos rendimentos. Pesquisa de Emprego e Desemprego (PED): Boletim de março de 2013. Disponível em: https://www.dieese.org.br/analiseped/2013/2013 pedmulhermet.pdf. Acesso em: 02 set. 2019.

FOUCAULT, Michel. Em defesa da sociedade: curso no Collège de France (1975-1976). São Paulo: Martins Fonte, 1999a.

FOUCAULT, Michel. Vigiar e punir: nascimento da prisão. 20ª Edição. Petrópolis: Vozes, 1999 b.

FOUCAULT, Michel. Microfísica do poder. $4^{\mathrm{a}}$ Edição. Rio de Janeiro: Edições Graal, 1984.

GALEANO, Eduardo H. As veias abertas da América Latina. Porto Alegre: L\&PM, 2016. 
HILÁRIO, Leomir Cardoso. Da biopolítica à necropolítica: variações foucaultianas na periferia do capitalismo. Sapere Aude, Minas Gerais, v. 7, n. 12, p. 194-210, jan./jun. 2016. DOI: https://doi.org/10.5752/P.2177-6342.2016v7n13p194.

http://periodicos.pucminas.br/index.php/SapereAude/article/view/11813. Acesso em: 20 set. 2019.

IPEA. Mulheres e trabalho: breve análise do período 2004-2014. Nota técnica nº 24. IPEA: Brasília, março de 2016.2 Disponível em: http://repositorio.ipea.gov.br/bitstream/11058/6524/1/Nota_n24_Mulheres_trabalho.pdf. Acesso em: 20 set. 2019.

LIMA, Fátima. Bio-necropolítica: diálogos entre Michel Foucault e Achille Mbembe. Arq. bras. psicol., Rio de Janeiro, v. 70, n. spe, p. 20-33, 2018. Disponível em: http://pepsic.bvsalud.org/scielo.php?script=sci_arttext\&pid=S1809-

52672018000400003\&lng=pt\&nrm=iso. Acessos em: 24 set. 2019.

LUGONES, Maria. Rumo a um feminismo descolonial. Revista de Estudos Feministas, Florianópolis, v. 22, n. 3, 320, p. 935-952, 2014. DOI: https://doi.org/10.1590/\%25x. Disponível em: https://periodicos.ufsc.br/index.php/ref/article/view/36755. Acessos em: 24 set. 2019.

MBEMBE, Achille. Políticas de Inimizade. Lisboa: Antígona, 2017.

MBEMBE, Achille. Necropolítica. Arte \& Ensaios, Rio de Janeiro, n. 32, p. 123-152, 2016. Disponível em: https://revistas.ufrj.br/index.php/ae/article/view/8993. Acesso em: 20 set. 2019.

MARQUES, Rosa Maria; UGINO, Camila Kimie. O Brasil é chamado à ordem. Argumentum, Vitória, v. 9, n. 3, p. 8-23, set./dez. 2017. DOI: https://doi.org/10.18315/argum..v9i3.17944. Disponível em: http://www.periodicos.ufes.br/argumentum/article/view/17944. Acesso em: 11 set. 2019.

QUIJANO, Aníbal (2010). Colonialidade do poder e classificação social. In: . SANTOS, Boaventura de Souza; MENESES, Maria Paula (Orgs). Epistemologias do sul. São Paulo: Cortez, p. 84-130.

SANTOS, Aline Mendonça. Questão social, desemprego, precarização e produção da pobreza: os reflexos para a produção da economia solidária no Brasil. Praxis Sociológica, Castilla-La Mancha,

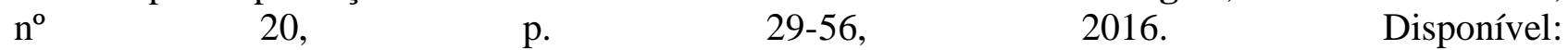
https://estudogeral.sib.uc.pt/bitstream/10316/35333/1/Quest\%c3\%a3o\%20social\%2c\%20desempreg o\%2c\%20precariza\%c3\%a7\%c3\%a3o\%20e\%20produ\%c3\%a7\%c3\%a3o\%20da\%20pobreza.pdf. Acesso em 20 set. 2019. 